\title{
Self-Esteem dan Hardiness Sebagai Prediktor Successful Aging Lansia yang Tinggal Sendiri
}

\author{
Briskia Grace Augita Amaheka ${ }^{(1)}$, Christiana Hari Soetjiningsih ${ }^{(1)}$ \\ briskia.amaheka22@gmail.com \\ ${ }^{(1)}$ Fakultas Psikologi, Universitas Kristen Satya Wacana, Salatiga, Indonesia
}

\begin{abstract}
The purpose of this study is to examine the effect of self-esteem and hardiness on successful aging in the elderly who live alone. This research is a quantitative study with 142 participants who lived alone (at least living with a partner, not with children) in 6 cities in Central Java, which were obtained using a purposive sampling technique. Data were obtained using Successful Aging Scale (Rowe and Kahn), Rosenberg Self-Esteem Scale (Rosenberg) and Short Hardiness Scale (Bartone). The results of this study indicate that simultaneous selfesteem and hardiness as predictors of successful aging in elderly people who live alone (minimum life with a partner, not with children), seen from the obtained $F_{\text {count }}$ value of 35.963 and $F_{\text {table }}$ of $2.670\left(F_{\text {count }}>F_{\text {table }}\right)$ and a significance value of $0.000(p<0.05)$. That is, this study provides practical implications, namely when the elderly who live alone have high selfesteem and hardiness, it will affect the high successful aging of the elderly in their old age.
\end{abstract}

Keywords: successful aging; self-esteem; hardiness

Tujuan dilakukannya penelitian ini yaitu untuk menguji pengaruh self-esteem dan hardiness terhadap successful aging pada lansia yang tinggal sendiri. Penelitian ini merupakan penelitian kuantitatif dengan partisipan berjumlah 142 orang lanjut usia yang tinggal sendiri (minimal hidup bersama pasangan, tidak bersama dengan anak) yang berdomisili di 6 kota di Jawa Tengah, yang diperoleh dengan menggunakan teknik purposive sampling. Data diperoleh menggunakan Skala Successful Aging (Rowe dan Kahn), Rosenberg Self-Esteem Scale (Rosenberg) dan Short Hardiness Scale (Bartone). Hasil dari penelitian ini menunjukkan bahwa self-esteem dan hardiness secara simultan dapat menjadi prediktor successful aging pada lansia yang tinggal sendiri (minimal hidup bersama pasangan, tidak bersama dengan anak), dilihat dari diperolehnya nilai $F_{\text {hitung }}$ sebesar 35.963 dan $F_{\text {tabel }}$ sebesar $2.670\left(\mathrm{~F}_{\text {hitung }}>\mathrm{F}_{\text {tabel }}\right)$ serta nilai signifikansi $0.000 \quad(\mathrm{p}<0.05)$. Artinya, penelitian ini memberikan implikasi praktis yaitu ketika lansia yang hidup sendiri memiliki self-esteem dan hardiness yang tinggi maka akan berpengaruh pada tingginya successful aging lansia di masa tuanya.

Kata kunci: successful aging; self-esteem; hardiness; lansia yang tinggal sendiri

Received: September 17, 2018 Accepted: March 5, 2019

How to cite: Amaheka, B. G. A., \& Soetjiningsih, C. H. (2019). Self-Esteem dan Hardiness Sebagai Prediktor Successful Aging Lansia yang Tinggal Sendiri. MEDIAPSI, 5(1), 30-39. doi: https://doi.org/10.21776/ub.mps.2019.005.01.3

\section{Pendahuluan}

Pada tahapan lanjut usia (lansia), individu akan mengalami berbagai perubahan yang merupakan proses lanjutan dari proses tumbuh kembang masa sebelumnya. Dalam masa ini individu akan mengalami banyak kemunduran secara bertahap meliputi aspek fisik, psikologis, dan sosial. Kemunduran yang terjadi pada masing-masing lansia berbedabeda karena tergantung faktor-faktor yang memengaruhi seperti genetik, pola hidup, lingkungan sekitar, kondisi mental, asupan gizi dan pekerjaan sehari-hari (SurveyMETER \& CAS UI, 2013). Di Indonesia, nampaknya masih banyak lansia yang tinggal bersama keluarga, dan sebagian ada yang tinggal sendiri atau tinggal di panti wreda. Para lansia 
yang memilih untuk tinggal sendiri dikarenakan beberapa faktor seperti keputusan dari dirinya sendiri, kepribadian, keterpaksaan, latar belakang keluarga dan adanya perubahan sistem keluarga serta bergesernya nilai-nilai budaya. Meski demikian, dalam penelitian yang dilakukan oleh Kusumiati (2009) menyebutkan bahwa ketika lansia memilih hidup sendiri maka akan berdampak secara positif maupun negatif.

Dampak positif lansia yang tinggal sendiri yaitu akan mampu mengekspresikan diri dengan kebebasan yang dimiliki, mampu mandiri dalam melakukan aktivitasnya seharihari, aging in place, dan lansia dapat memiliki relasi yang baik dengan lingkungan sekitarnya. Sementara, dampak negatif yang dapat muncul ialah akan merasa kesepian, tidak adanya penghasilan untuk memenuhi kebutuhan sehari-hari, takut untuk menjadi korban kejahatan dan masalah-masalah kesehatan akibat kurangnya dukungan keluarga (Kusumiati, 2009).

Data Susenas tahun 2016 (Badan Pusat Statistik, 2016) memperlihatkan bahwa persentase lansia di Indonesia mengalami peningkatan yaitu dari $8.69 \%$ menuju $9.03 \%$ dari populasi penduduk di tahun 2017. Dapat dikatakan bahwa Indonesia merupakan salah satu negara berkembang yang mulai memasuki era penduduk menua (ageing population). Hal ini senada dengan pernyataan Soeweno (Kementerian Kesehatan Republik Indonesia, 2017) yang menyatakan bahwa suatu negara dikatakan berstruktur tua jika mempunyai populasi lansia di atas tujuh persen. Di Indonesia, propinsi yang berstruktur penduduk tua terbesar yaitu D.I. Yogyakarta (13.81\%), Jawa Tengah dengan populasi lansia yang mencapai 4,312,322 jiwa (12.59\%) dan Jawa Timur (12.25\%).
Meningkatnya jumlah lansia di Indonesia seharusnya diikuti dengan adanya perubahan dalam strategi pelayanan dan penanganan serius terkait kesehatan (Pratikwo dkk., 2006) sehingga dalam menjalani masa tua, para lansia memiliki kesehatan yang baik, lingkungan sosial yang kuat, kondisi ekonomi yang memadai, dan terutama mendapatkan dukungan keluarga agar menjadi lansia yang bahagia (Departemen Kesehatan Republik Indonesia, 1991). Ketika lansia merasakan kebahagiaan dalam hidupnya maka dapat dikatakan bahwa lansia mampu menjadi seorang lansia yang memiliki successful aging (menjadi lansia yang baik atau berhasil).

Successful aging menurut Berkman dkk. (1993) dan Rowe dan Kahn (1987; dalam Schulz, 1996) yaitu fokus pada keberfungsian tubuh dan tidak adanya kecacatan sebagai pengukur keberhasilan. Menurut Rowe dan Kahn (1997) successful aging terkait dengan komponen-komponen yang mendukung terwujudnya successful aging pada lansia yaitu meminimalisir risiko munculnya berbagai penyakit dan akibat yang berhubungan dengan penyakit tersebut, mengelola secara baik fungsi-fungsi fisik maupun psikis, dan terlibat aktif dalam kehidupan) serta satu komponen tambahan yaitu spiritualitas positif (Crowther dkk., 2002).

Ada berbagai faktor yang memengaruhi tercapainya successful aging. Hasil penelitian Cha dkk. (2014) pada 305 lansia yang berusia 60 tahun ke atas di Korea, melaporkan bahwa successful aging dipengaruhi oleh self-esteem, self-achievement, hubungan interpersonal, dan efikasi diri. Di antara 4 faktor tersebut, selfesteem menjadi faktor yang paling berpengaruh terhadap successful aging pada lansia di Korea. Selain itu, penelitian yang dilakukan oleh Candra dkk. (2016) 
menunjukkan bahwa terdapat hubungan positif yang signifikan antara self-esteem dengan successful aging. Rosenberg (1965) mendefinisikan self-esteem sebagai evaluasi positif maupun negatif terhadap diri sendiri, mencakup aspek-aspek penerimaan diri dan penghormatan diri. Menurut Cho (2011) selfesteem adalah pengenalan dan penerimaan positif akan diri sendiri sebagai orang yang berharga. Pendapat senada dikemukakan Ghufron (2010) bahwa self-esteem merupakan penilaian positif atau negatif yang berhubungan dengan konsep diri yang dimiliki individu. Penelitian yang dilakukan Robins tahun 2010 (dalam Setiyawati dkk., 2017) menunjukkan bahwa self-esteem mencapai puncaknya pada usia 60 tahun, dan setelah melewati usia itu (60-100 tahun) maka individu akan mengalami penurunan selfesteem secara signifikan. Hal ini mungkin saja terjadi karena terkait dengan kondisi lansia yang semakin hari semakin menurun yang mana akan memengaruhi perubahan selfesteem (Candra dkk., 2016) dimana terlihat dari munculnya perasaan tidak berharga, tidak berguna dan tidak berdaya, merasakan sedih dan kecewa yang mendalam serta gejala psikososial lainnya. Oleh karena itu sebaiknya lansia dapat mengatasi perubahan-perubahan yang muncul tersebut dengan melakukan penyesuaian diri dan aktif dalam kegiatankegiatan seusianya.

Faktor lainnya yang memengaruhi successful aging yaitu hardiness, partisipasi sosial aktif, memiliki banyak teman dan ketertarikan dalam hidup (Vance \& Robinson, 2004). Faktor hardiness disebutkan pula oleh Reichstadt dkk. (2007) sebagai faktor yang memengaruhi dalam successful aging. Kobasa dkk. (1982) menjelaskan hardiness sebagai karakteristik kepribadian yang berfungsi dalam melawan berbagai permasalahan dan tantangan dalam hidup karena individu percaya bahwa semua beban dan masalah yang muncul tidak mungkin dihindari sehingga harus dihadapi dengan baik dan tepat. Terdapat tiga aspek hardiness yaitu kontrol, komitmen dan tantangan. Dengan semakin bertambahnya usia maka akan banyak permasalahan atau tantangan dalam hidup. Namun ketika lansia mampu menjalani hidup secara positif dengan berbagai tantangan yang ada maka dapat dikatakan bahwa lansia memiliki hardiness yang tinggi.

Berdasar uraian yang telah dipaparkan, penulis tertarik mengaji successful aging berkaitan dengan self-esteem dan hardiness pada lansia yang tinggal sendiri (minimal hidup bersama pasangan, tidak bersama dengan anak). Masih sangat sedikit ditemui penelitian dengan partisipan lansia yang mengaitkan ketiga variabel tersebut secara bersama. Sebagian besar penelitian hanya membahas secara parsial hubungan maupun pengaruh antar variabel bebas dan tergantung. Nicholas (1993), sebagai contoh, meneliti tentang hardiness, self-care practices and perceived health status in older adults. Tavares dkk. (2016) membahas tentang quality of life and self-esteem among the elderly in the community. Selain itu, Franak dkk. (2015) meneliti tentang self-esteem pada lansia yang mengunjungi healthcare centers dan Nesami dkk. (2016) meneliti association between self-care behaviors anf self-esteem of rural elderlies.

Perumusan masalah dari penelitian ini yaitu apakah ada pengaruh self-esteem dan hardiness secara bersama terhadap successful aging. Hipotesis yang diajukan dalam penelitian ini yaitu ada pengaruh self-esteem dan hardiness secara bersama terhadap successful aging. 


\section{Metode}

\section{Desain penelitian}

Penelitian ini merupakan penelitian kuantitatif yang bertujuan untuk membuktikan pengaruh self-esteem dan hardiness secara simultan terhadap successful aging. Adapun variabel-variabel dalam penelitian ini, yaitu:

1. Variabel bebas: self-esteem dan hardiness.

2. Variabel tergantung: successful aging.

\section{Partisipan}

Partisipan penelitian berjumlah 142 lansia yang diperoleh dengan menggunakan teknik purposive sampling yang mana dalam teknik ini yang telah ditentukan. Karakteristik partisipan yaitu lansia berusia 60 tahun keatas, lansia yang tinggal sendiri (minimal hidup bersama pasangan, tidak bersama dengan anak), masih mampu berkomunikasi dengan baik, dan bersedia mengisi skala psikologis yang dibagikan. Selain itu, domisili partisipan di provinsi Jawa Tengah yaitu di kota Salatiga, kota Semarang, kota Magelang, Solo, Pekalongan, dan Tegal.

\section{Instrumen penelitian}

Penelitian ini menggunakan tiga skala psikologis, yaitu:

1. Skala Successful Aging. Skala ini dikembangkan peneliti dengan mengacu pada komponen successful aging yang diungkapkan oleh Rowe dan Kahn (1997) dan Crowther dkk. (2002). Sesudah uji coba, skala ini terdiri dari 10 aitem dengan nilai Cronbach's alpha sebesar 0.875 .

2. Skala Self-Esteem dari Rosenberg (Rosenberg Self-Esteem Scale). Sesudah uji coba, skala ini terdiri dari 10 aitem dengan nilai Cronbach's alpha 0.907.

3. Skala Hardiness (Short Hardiness Scale) dari Bartone yang menggunakan teori Kobasa (1979) dan Maddi dan Kobasa (1984). Sesudah uji coba, skala ini terdiri dari 10 aitem dengan nilai Cronbach's alpha sebesar 0.893 .

\section{Hasil}

\section{Statistik deskriptif}

Partisipan dalam penelitian ini berjumlah 142 orang yang berdomisili di Jawa Tengah, dengan perincian seperti berikut: Salatiga sebanyak 25 orang, Semarang sebanyak 25 orang, Surakarta sebanyak 22 orang, Magelang sebanyak 25 orang, Pekalongan sebanyak 25 orang dan Tegal sebanyak 20 orang.

Tabel 1

Jumlah dan Presentase Partisipan Berdasarkan Jenis Kelamin

\begin{tabular}{ccc}
\hline Jenis Kelamin & Jumlah & Presentase (\%) \\
\hline Laki-laki & 24 & $16.9 \%$ \\
Perempuan & 118 & $83.1 \%$ \\
\hline TOTAL & 142 & $100 \%$ \\
\hline
\end{tabular}

Tabel 2

Jumlah dan Presentase Partisipan Berdasarkan Usia

\begin{tabular}{ccc}
\hline Kategori Usia & Jumlah & Presentase (\%) \\
\hline 60 & 8 & $5.6 \%$ \\
\hline $61-65$ & 32 & $22.5 \%$ \\
\hline $66-70$ & 51 & $35.9 \%$ \\
\hline $71-75$ & 17 & $12 \%$ \\
\hline $76-80$ & 24 & $16.9 \%$ \\
\hline $81-85$ & 5 & $3.5 \%$ \\
\hline $86-90$ & 2 & $1.4 \%$ \\
\hline$\geq 95$ & 3 & $2.1 \%$ \\
\hline TOTAL & 142 & $100 \%$ \\
\hline
\end{tabular}

Dari Tabel 1 diketahui bahwa jumlah partisipan penelitian berjenis kelamin perempuan lebih banyak (118 orang) dibandingkan partisipan laki-laki (24 orang). 
Dari Tabel 2, berdasarkan kategori usia, menunjukkan bahwa sebagian besar partisipan berada pada rentang usia 66-70 tahun (51 orang) dan yang paling sedikit berada pada rentang usia 86-90 tahun (2 orang).

Tabel 3

Data Deskriptif

\begin{tabular}{ccccc}
\hline & Yariabel & \multicolumn{3}{c}{ Frekuensi } \\
\cline { 3 - 5 } Interval & $\begin{array}{c}\text { Successful } \\
\text { Kategoring }\end{array}$ & $\begin{array}{c}\text { Self- } \\
\text { esteem }\end{array}$ & Hardiness \\
\hline $10 \leq \mathrm{x} \leq 20$ & Rendah & 1 & 2 & 4 \\
\hline $20 \leq \mathrm{x} \leq 30$ & Sedang & 108 & 106 & 108 \\
\hline $30 \leq \mathrm{x} \leq 40$ & Tinggi & 33 & 34 & 30 \\
\hline \multicolumn{2}{c}{ TOTAL } & & 142 \\
\hline
\end{tabular}

Berdasarkan data deskriptif pada Tabel 3, lansia yang tinggal sendiri sebagian besar yaitu sebanyak 108 lansia memiliki successful aging pada kategori sedang. Untuk selfesteem, sebagian besar lansia yang tinggal sendiri berada dalam kategori sedang yaitu sebanyak 106 lansia, sedangkan untuk hardiness sebagian besar lansia yang tinggal sendiri berada dalam kategori sedang yaitu sebanyak 108 lansia.

\section{Uji asumsi}

\section{Uji normalitas}

Uji normalitas dalam penelitian ini menggunakan uji residual KolmogrovSmirnov. Hasil menunjukkan bahwa nilai signifikansi yaitu sebesar 0.200 ( $>>0.05)$, sehingga dapat dikatakan bahwa data berdistribusi normal.

\section{Uji multikolinearitas}

Hasil menunjukkan bahwa nilai tolerance sebesar $0.937(>0.10)$ dan nilai VIF sebesar $1.067(<10)$, sehingga dapat dikatakan bahwa tidak terjadinya multikolinearitas antar variabel bebas. Artinya, model regresi layak untuk digunakan.

\section{Uji heterokedasitas}

Pada diagram pancar (Gambar 1), terlihat bahwa tidak terjadinya heterokedasitas di mana terdapat titik-titik yang berpencar tidak membentuk pola tertentu, titik-titik tersebut menyebar di atas dan di bawah angka 0 pada sumbu Y.

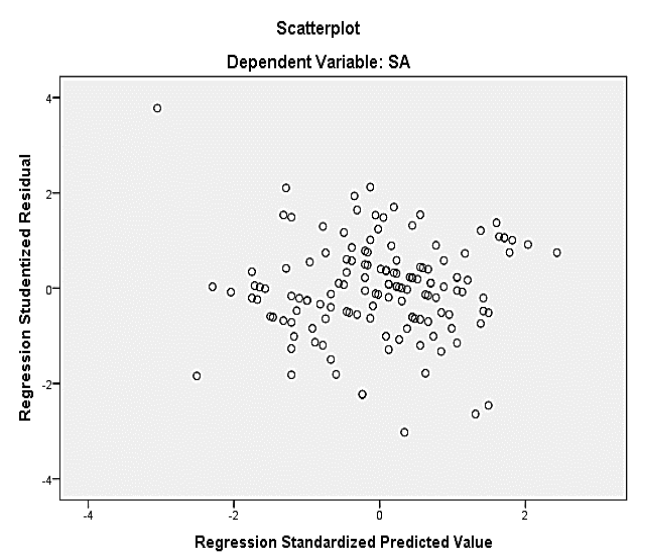

Gambar 1. Diagram Pancar Heterokedasitas

\section{Uji linearitas}

Berdasarkan perhitungan, diperoleh nilai $\mathrm{F}_{\text {beda }}$ sebesar 1.326 dan nilai signifikansi 0.197 (p>0.05). Artinya, dapat dikatakan bahwa terdapat linearitas antara successful aging dan self-esteem. Perhitungan linearitas antara successful aging dan hardiness, diperoleh nilai $F_{\text {beda }}$ sebesar 1.609 dan nilai signifikansi 0.071 (p>0.05). Artinya, dapat dikatakan bahwa terdapat linearitas antara successful aging dan hardiness.

\section{Uji hipotesis}

\section{Uji signifikan simultan (Uji F)}

Hasil uji signifikansi pada variabel selfesteem dan hardiness terhadap successful aging pada lansia yang tinggal sendiri yaitu sebagai berikut (Tabel 4):

Tabel 4

Uji Signifikansi Regresi Berganda

\begin{tabular}{ccc}
\hline $\mathbf{F}_{\text {tabel }}$ & $\mathbf{F}_{\text {hitung }}$ & Nilai Signifikansi \\
\hline 2.670 & 35.963 & 0.000 \\
\hline
\end{tabular}

Dari Tabel 4, $F_{\text {hitung }}>F_{\text {tabel }}$ dan taraf signifikansi $\mathrm{p}<0.05$ yang bermakna ada pengaruh self-esteem dan hardiness secara 
besama terhadap successful aging. Dapat disimpulkan bahwa self-esteem dan hardiness secara simultan menjadi prediktor successful aging pada lansia yang tinggal sendiri.

\section{Koefisien determinasi}

Tabel 5

R Kuadrat

\begin{tabular}{ccc}
\hline $\mathbf{R}$ & $\mathbf{R}^{\mathbf{2}}$ & ${\text { Adjusted } \mathbf{R}^{\mathbf{2}}}$ \\
\hline 0.583 & 0.340 & 0.330 \\
\hline
\end{tabular}

Dari Tabel 5 dapat dilihat nilai koefisien determinasi $\left(\mathrm{R}^{2}\right)$ yaitu sebesar 0.340 sehingga dapat dikatakan bahwa sumbangan self-esteem dan hardiness terhadap successful aging sebesar 34\%, sedangkan sisanya $66 \%$ dijelaskan oleh variabel lain yang tidak diteliti dalam penelitian ini.

\section{Diskusi}

Berdasarkan hasil analisa, terlihat hasil $F_{\text {hitung }}>F_{\text {tabel }}$ dengan taraf signifikansi $p<0.05$ sehingga dapat dikatakan hipotesis diterima. Hal ini menunjukkan bahwa self-esteem dan hardiness secara simultan dapat menjadi prediktor successful aging pada lansia yang tinggal sendiri. Atau dengan kata lain, pencapaian successful aging dipengaruhi oleh self-esteem dan hardiness. Artinya tinggi rendahnya self-esteem dan hardiness secara bersama-sama dapat digunakan dalam meningkatkan successful aging pada lansia yang tinggal sendiri.

Lansia yang hidup seorang diri rentan mengalami berbagai macam penyakit tetapi ketika lansia memiliki self-esteem yang tinggi maka lansia akan terhindar dari masalahmasalah tersebut. Selain itu, Rosenberg (dalam Widiharto, 2007) mengatakan bahwa lansia harus dapat menerima dan menghormati kondisi dirinya sendiri. Sehingga, dengan selfesteem yang tinggi lansia cenderung merasa puas, bahagia serta memiliki keyakinan yang kuat akan kemampuan dalam dirinya sendiri. Dayakisni (dalam Sari, 2013) mengatakan bahwa terbentuknya self-esteem yang positif/tinggi didorong oleh kemampuan individu dalam mengontrol diri sendiri dengan baik. Tidak hanya itu saja, Amir (2010) mengatakan bahwa dengan memiliki keyakinan spiritual yang terbangun dengan baik maka lansia dapat memiliki self-esteem yang tinggi. Hal ini diperkuat oleh hasil penelitian Leppert (dalam Syam'ani, 2013) yang mengatakan bahwa aspek spiritual berkorelasi sangat kuat terhadap peningkatan kesehatan psikologis lansia. Selain itu, Park dkk. (dalam Franak, Alireza, \& Malek, 2015) menemukan bahwa lansia dengan aktivitas fisik yang baik menjadi lebih berhasil menjalani masa tuanya. Oleh karena itu, dalam self-esteem, pentingnya aspek spiritual dan aktivitas fisik di masa tua agar dapat mencapai successful aging (lansia yang sukses).

Selain self-esteem, hardiness juga berpengaruh terhadap peningkatan successful aging lansia yang tinggal sendiri. Kepribadian hardiness (ketangguhan) pada lansia membuat mereka mampu beradaptasi dalam menghadapi berbagai peristiwa di masa tuanya. Kobasa, Maddi, dan Kahn (1982) menyebutkan bahwa perlu adanya kontrol, komitmen dan tantangan dalam menjalani hidup. Hal ini terutama diperlukan oleh para lansia yang mulai mengalami penurunan kondisi fisik, sosial dan psikis. Lansia dengan hardiness tinggi dapat menerima berbagai perubahan dalam dirinya dan menjadi tetap sehat meskipun mengalami kejadian-kejadian yang penuh dengan stressor (Ariyanti \& Indriana, 2015). Ketika lansia mampu menjaga kesehatannya di masa tua dengan melakukan adaptasi yang baik terhadap perubahan diri maka dapat terwujudnya successful aging pada lansia. 
Kemampuan lansia dalam menghadapi berbagai tantangan dan perubahan di masa tua membuat lansia memperoleh self-esteem dan hardiness yang tinggi untuk dapat beradaptasi dilingkungan sehingga lansia mampu menghadapi kehidupan masa tuanya dengan berhasil karena kualitas hidup yang meningkat pula atau dengan kata lain mampu menjadi lansia yang sukses (successsful agers). Hal ini didukung dari penelitian yang dilakukan oleh Jopp dan Rott (dalam Widiasari \& Nuryoto, 2010) yang menyebutkan bahwa lansia akan merasa bahagia dengan memiliki kemampuan beradaptasi yang dipengaruhi oleh keyakinan pada diri sendiri serta tingkah laku dalam kehidupan sehari-hari. Dengan demikian, dapat dikatakan bahwa untuk mencapai successful aging pada lansia yang tinggal sendiri, diperlukannya self-esteem dan hardiness di masa tua.

Dalam penelitian ini juga ditemukan sumbangan efektif self-esteem dan hardiness dalam memengaruhi pencapaian successful aging pada lansia yang tinggal sendiri yaitu sebesar 34\% sedangkan sisanya sebanyak $66 \%$ dipengaruhi oleh faktor lain yang tidak diteliti dalam penelitian ini. Bila dilihat, faktor lain yang memengaruhi tercapainya successful aging pada lansia yang tinggal sendiri di antaranya resiliensi, aktivitas sehari-hari, nilainilai dalam hidup dan lain sebagainya.

Dengan demikian, berdasarkan uraian di atas, simpulan penelitian ini yaitu:

1. Ada pengaruh self-esteem dan hardiness secara simultan terhadap successful aging pada lansia yang tinggal sendiri. Selfesteem dan hardiness secara simultan sebagai prediktor successful aging.

2. Sumbangan efektif self-esteem dan hardiness terhadap successful aging sebesar
$34 \%$ sedangkan sisanya sebanyak $66 \%$ dipengaruhi oleh faktor lainnya yang tidak diteliti dalam penelitian ini.

3. Successful aging sebagian besar lansia (108 lansia) ada pada kategori sedang, sehingga dapat dikatakan bahwa sebagian besar lansia yang tinggal sendiri belum mencapai successful aging sesuai konsep Rowe dan Kahn (1997). Selain itu, self-esteem dan hardiness sebagian besar lansia yang tinggal sendiri juga berada dalam kategori sedang.

Berdasarkan hasil penelitian ini, maka dapat disampaikan beberapa saran, yaitu:

1. Bagi para lansia agar perlu memahami serta meningkatkan pemahaman terkait successful aging karena pentingnya menjaga dan menjadi successful agers (lansia yang sukses atau berhasil). Untuk itu lansia harus memiliki nilai-nilai positif, optimis, dan tetap tangguh dalam menjalankan hidup dengan berbagai tantangan yang ada.

2. Bagi peneliti selanjutnya, dengan masih sedikitnya penelitian tentang kaitan selfesteem, hardiness, dan successful aging pada lansia yang tinggal sendiri, maka penelitian ini dapat menjadi acuan untuk penelitian selanjutnya. Peneliti selanjutnya dapat mengaitkan dengan variabel-variabel lain misalnya dukungan sosial, nilai-nilai yang dianut, kearifan lokal, dan pemanfaatan teknologi. Selain itu, untuk menggali secara mendalam terkait masalah successful aging ini dapat digunakan metode penelitian kualitatif.

3. Bagi pemerintah, diharapkan agar kebijakan-kebijakan pemerintah lebih melihat serta memperhatikan kebutuhan lansia. Pemerintah perlu melakukan 
perbaikan kembali peraturan bagi para lansia agar lansia dapat diberdayakan untuk mencapai successful aging.

\section{Daftar Pustaka}

Amir, S. (2010). Hubungan antara kesehatan spiritual dengan kesehatan jiwa pada lansia muslim di sasana tresna werdha Jakarta Timur. Tesis diterbitkan. Depok: Universitas Indonesia.

Ariyanti, M., \& Indriana, Y. (2015). Hardiness dan kecenderungan post power syndrome pada lanjut usia pensiunan Pegawai Negeri Sipil (PNS) anggota Persatuan Wredatama Republik Indonesia (PWRI) Kecamatan Gajah Mungkur Semarang. Jurnal Empati, 4(1), 100-105. Diambil dari: https://ejournal3.undip.ac.id/index.php/ empati/article/view/13124

Badan Pusat Statistik. (2016). Statistik Penduduk Lanjut Usia 2016. Jakarta: Badan Pusat Statistik.

Baltes, M. M., \& Cartensen, L. L. (1996). The process of successful ageing. Ageing and Society, 16, 397-422. doi: https://doi.org/10.1017/S0144686X000 $\underline{03603}$

Bartone, P. T. (1995). A Short Hardiness Scale. Germany: Walter Reed Army Institute of Research US Army Medical Research Unit. doi: https://doi.org/10.21236/ADA298548

Berkman, L. F., Seeman, T. E., Albert, M., Blazer, D., Khan, R., Mohs, R., . . . Rowe, J. (1993). High, usual and impaired functioning in communitydwelling older men and women: findings from the MacArthur foundation research network on successful aging. Journal of Clinical Epidemiology, 46(10), 11291140. doi: https://doi.org/10.1016/08954356(93)90112-E

Candra, A., Tavip, D. W., \& Ani, S. (2016). Hubungan antara aktivitas fisik dan pola makan dengan kejadian obesitas pada remaja di SMA Laboratorium Malang. Nursing News: Nursing News : Jurnal Ilmiah Keperawatan, 1(1). Diambil dari: https://publikasi.unitri.ac.id/index.php/fi kes/article/view/392

Cha, N. H., Seo, J. E., \& Sok, S. R. (2014). Factors influencing the successful aging of older Korean adults. Contemporary Nurse, 41(1), 78-87. doi: https://doi.org/10.5172/conu.2012.41.1. $\underline{78}$

Cho, J. (2011). Successful aging and developmental adaptation of oldest-old adults. Disertasi dipublikasikan. Ames: Iowa State University.

Crowther, M. R., Parker, M. W., Achenbaum, W. A., Larimore, W. L., \& Koenig, H. G. (2002). Rowe and Kahn's model of successful aging revisited. The Gerontologist, 42(5), 613-620. doi: https://doi.org/10.1093/geront/42.5.613

Departemen Kesehatan Republik Indonesia. (1991). Pedoman Teknis Penyediaan, Pengolahan, dan Penyaluran Makanan Rumah Sakit. Jakarta: Depkes RI.

Franak, J., Alireza, K., \& Malek, M. (2015). Self-esteem among the elderly visiting the healthcare centers in KermanshahIran. Global Journal of Health Science, 7(5), 352-358. doi: https://dx.doi.org/10.5539\%2Fgjhs.v7n $\underline{5 \mathrm{p} 352}$ 
Ghufron. (2010). Teori-teori Perkembangan. Bandung: Refika Aditama.

Kementerian Kesehatan Republik Indonesia. (2018, Mei 14). Populasi lansia diperkirakan terus meningkat hingga tahun 2020. Diambil dari: http://www.depkes.go.id/article/view/13 110002/populasi-lansia-diperkirakanterus-meningkat-hingga-tahun2020.html

Kobasa, S. C. (1979). Stressful life events, personality, and health: An inquiry into hardiness. Journal of Personality and Social Psychology, 37(1), 1-11. doi: https://doi.org/10.1037/0022$\underline{3514.37 .1 .1}$

Kobasa, S. C., Maddi. S. R., \& Kahn, S. (1982). Hardiness and health: a prospective study. Journal of Personality and Social Psychology, 42(1), 168-177. doi: https://doi.org/10.1037/0022351$\underline{4.42 .1 .168}$

Kusumiati, R. Y. E. (2009). Tinggal sendiri di masa lanjut usia. Humanitas, 6(1), 2441.

Maddi, S. R., \& Kobasa, S. C. (1984). The Hardy Executive: Health Under Stress. Homewood: Dow Jones-Irwin.

Nesami, M. B., \& Goudarzian, A. H. (2016). Association between self-care behaviors and self-esteem of rural elderlies. Mater Sosiomed, 28(1), 41-46. doi: https://dx.doi.org/10.5455\%2Fmsm.201 $\underline{6.28 .41-45}$

Nicholas, P. K. (1993). Hardiness, self-care practices and perceived health status in older adults. Joumal of Advanced Nursing, 18(7), 1085-1094. doi: https://doi.org/10.1046/j.13652648.1993.18071085.x

Pratikwo, S., Pietojo, H., \& Widjanarko, B. (2006). Analisis pengaruh faktor nilai hidup, kemandirian, dan dukungan keluarga terhadap perilaku sehat lansia di kelurahan medono kota pekalongan. Jurnal Promosi Kesehatan Indonesia, l(2), 13-22. https://doi.org/10.14710/jpki.1.2.13-22

Reichstadt, J., Depp, C. A., Palinkas, L. A., Folsom, D. P., \& Jeste, D. V. (2007). Building blocks of successful aging: a focus group study of older adults' perceived contributors to successful aging. The American Journal of Geriatric Psychiatry 15(3), 194-201. doi:

https://doi.org/10.1097/JGP.0b013e318 $\underline{030255 f}$

Rosenberg, M. (1965). Society and the Adolescent Self-Image. Princeton, NJ: Princeton University Press.

Rowe, J. W., \& Kahn, R. L. (1987). Human aging: usual and successful. Science, 237(4811), 143-149. doi: https://doi.org/10.1126/science.3299702

Rowe, J. W., \& Khan, R. L. (1997). Successful aging. Gerontologist, 37(4), 433-440. doi:

https://doi.org/10.1093/geront/37.4.433

Sari, N. D. K. (2013). Gambaran Self-Esteem pada lansia di panti wredha Salib Putih Salatiga Jawa Tengah. Skripsi dipublikasikan. Salatiga: Universitas Kristen Satya Wacana Salatiga.

Setiyawati, M. R., Titik, S., \& Budi, W. (2017). Perbedaan tingkat harga diri lansia yang memiliki pasangan hidup 
dan tidak memiliki pasangan hidup di Desa Candisari Purwodadi Grobogan. Karya Ilmiah. Diambil dari: http://ejournal.stikestelogorejo.ac.id/ind ex.php/ilmukeperawatan/article/view/66 $\underline{7 / 665}$

Schulz, R., \& Heckhausen, J. (1996). A life span model of successful aging. American Psychologist, 51(7), 702-714. doi: $\quad$ http://dx.doi.org/10.1037/0003$\underline{066 X .51 .7 .702}$

SurveyMETER dan CAS UI. (2013). Satu Langkah Menuju Impian Lanjut Usia, Kota Ramah Lanjut Usia 2030. Diambil dari:

https://surveymeter.org/read/102/satulangkah-menuju-impian-lanjut-usiakota-ramah-lanjut-usia-2030

Tavares, D. M. dos S., Matias, T. G. C., Ferreira, P. C. dos S., Pegorari, M. S., Nascimento, J. S., \& Paiva, M. M. de. (2016). Quality of life and self-esteem among the elderly in the community. Ciência \& Saúde Coletiva, 21(11), 35573564. doi: http://dx.doi.org/10.1590/1413$\underline{812320152111.03032016}$

Vance, D. E., \& Robinson, F. P. (2004). Reconciling successful aging with HIV. Journal of HIV/AIDS \& Social Services, 3(1), 59-78. doi: https://doi.org/10.1300/J187v03n01_06

Widiasari, Y., \& Nuryoto, S. (2010). Dinamika psikologis pencapaian successful aging pada lansia yang mengikuti program yandu lansia. PSYCHO IDEA, 8(1). http://dx.doi.org/10.30595/psychoidea.v $\underline{8 i 1.227}$

Widiharto, C. A., Sandjaja, S. S., Eriany, P. (2010). Perilaku bullying ditinjau dari harga diri dan pemahaman moral anak.

Diambil

dari:

http://www.psikologi.tarumanagara.ac.i d/s2/wp-content/uploads/2010/09/21perilaku-bullyingditinjau-dari-hargadiri-dan-pemahaman-moral-anakchristhoporus-argo-widiharto-mpsi.pdf 